to waste his later years seeking an alternative to quantum theory.

It has only been possible here to sketch the nature of Dr Perkins's approach to creativity. He develops the points I have made in much more detail and makes many other illuminating suggestions. Although scholarly, his book is intended for the general public and is easy to read; it has only two faults - a tendency to write down to the reader and the inclusion of some singularly unattractive line drawings, which have little relevance to the text and serve to demonstrate only that not all artists are creative. He is of course aware that reducing the thought processes of creativity to those employed in everyday life does not explain the nature of those thought processes. But this reduction is a good beginning if only because it frees psychologists to get on with the task of explaining ordinary thought processes, and may help to stop other authors from continuing the existing tradition of producing turgid and obscure tomes on the mysteries of creation.

Stuart Sutherland is Director of the Centre for Research on Perception and Cognition at the University of Sussex.

\title{
Contradictions in theoretical chemistry
}

\section{H.C. Longuet-Higgins}

Chemistry, Quantum Mechanics and Reductionism. By Hans Primas. Pp.451. ISBN 3-540-10696-0. (Springer-Verlag: 1981.) DM 68, $\$ 32.40$.

"THE purpose of this book" writes Professor Primas "is to provide a deeper insight into the modern theories of molecular matter. It . . . is not meant to be a textbook; in many respects it has complementary goals. For good and bad reasons, most textbooks ignore the historical and philosophical aspects [of theoretical chemistry] and go ahead on the basis of crude simplifications; many even lie like the Devil and do not shrink from naive indoctrination".

Remarks such as these are well calculated, as the author intends, to ruffle the placid waters of theoretical chemistry. It is difficult enough, in all conscience, to explain the technicalities of quantum chemistry to lively young minds without having one's authority undermined by pronouncements such as "the theoretical basis of chemistry and biology is not safely in our hands". From a scientist of less achievement than Professor Primas such an assertion might well be greeted with open hostility in the community of theoretical chemists. How can it be reconciled with our evident ability to compute, with greater and greater accuracy, the dissociation energies, dipole moments, force constants and other properties of molecules? If the Schrödinger equation is not good enough for Professor Primas, has he a better one to propose?

Such a reaction to the opening pages of Chemistry, Quantum Mechanics and Reductionism would entirely miss the author's point. Anyone who has studied and taught theoretical chemistry for any length of time will know how difficult it is

The latest supplement to $A$ Bibliography of Ab Initio Molecular Wave Functions by W.G. Richards et al. has just been published by Oxford University Press. Covering the years 1978-1980, the book costs $£ 35$. to reconcile, in his own mind and the minds of his students, the elusive properties of sub-atomic particles with the evident permanence of large molecules and crystals. There is an almost irresistible temptation to suppose, and to imply, that there is one set of laws for the very small and another for the large - a proposition which is in flat contradiction with the orthodox interpretation of quantum mechanics. Professor Primas asserts that

The mode of activity exhibited by contemporary science strikingly reminds one of what Shapiro (1965) has called the paranoid style. It is characteristic of this style that bridges between related problems are broken down so that things remain neatly and rigidly separated. Scientists who cultivate a paranoid research style are usually extremely acute and intense, show an exorbitant respect for compartmentalisation and computers, and firmly demand complete autonomy for their narrowly fixed ideas ... The separation of philosophy and science has led to the so-called restricted world view and to the blindness of many experts who are entirely unaware of the abstract and isolating nature of modern science.

No, these are not the ravings of a iconoclast; in this long and fascinating book (it runs to over 400 pages) the author reveals a deep understanding and appreciation of the most difficult problems of quantum mechanics and of the acute paradoxes associated with its interpretation - or rather, with those alternative interpretations which do not violate experimental fact. He reveals himself as a master not only of the mathematics but also of the philosophy of science, and as a man who cares passionately about intellectual integrity, in the widest possible sense of that word. The book is uncompromisingly difficult, in an area where compromise would be unforgivable; but it is spiced with good plain questions of an acutely embarrassing kind: "What is quantum mechanics about?" "What is a classical description?" "Do isolated quantal systems exist at all?", "Does quantum mechanics apply to large molecular systems?"' and so on. I wonder how most theoretical chemists would answer these questions if some bright student were tiresome enough to ask them!

Chemistry, Quantum Mechanics and Reductionism is Professor Primas's own very positive contribution to the solution of some of these problems. The bestknown fully-developed interpretation of quantum mechanics is that of von Neumann, London and Bauer, and from this Professor Primas wants to remove just one unproved axiom, namely the universal validity of the superposition principle. $\mathrm{He}$ develops an alternative interpretation of his own, based on sophisticated algebraic concepts, of which the most important is that of a "W*-algebra". To master his ideas would obviously take much time and thought, but they are logically compatible (as the orthodox interpretation is not) with the attribution of "classical" properties to molecules - an assumption which all theoretical chemists use without apology when referring to the charge, the mass or the structure of an ordinary molecule. The book may be difficult, but it is quite unusually honest and thoughtful, and is likely to prove an invaluable antidote to the narrowness of outlook which is so often apparent in chemical theorizing.

H.C. Longuet-Higgins is Royal Society Research Professor at the University of Sussex.

\section{Crucial colonization}

\section{Barry Cox}

The Terrestrial Environment and the Origin of Land Vertebrates. The Systematics Association Special Volume, No. 15. Edited by A.L. Panchen. Pp.633. ISBN 0-12-544780-9. (Academic: 1981.) $£ 38, \$ 91.50$.

The earliest known tetrapods are the ichthyostegid amphibians, now known from Late Devonian rocks in both Greenland and Australia. From this beginning sprang a variety of larger "labyrinthodont" amphibians, apparently ancestral to the reptiles, as well as the smaller "lepospondyl" amphibians. The transformation of our interpretation of palaeogeography, as well as progress in such fields as Palaeozoic floras and both invertebrate and vertebrate faunas, makes this a timely volume. The 20 papers were originally given at a symposium in Newcastle upon Tyne in April 1979, which was organized by Alec Panchen, editor of the book.

Two of the papers are concerned with the geography of the world in which the first tetrapods evolved. Tarling analyses palaeomagnetic data and provides a series of continental reconstructions for the Early Devonian to Late Permian; he 